\title{
Innovation and the performance of Portuguese businesses: a 'SURE' approach
}

\section{Carla Susana Marques*, Chris Gerry and Susana Covelo}

Department of Economics, Sociology and Management, University of Trás-os-Montes e Alto Douro, Avenida Almeida Lucena, 1, Vila Real 5000-660, Portugal E-mail: smarques@utad.pt E-mail: cgerry@utad.pt E-mail: susanacovelo@gmail.com

*Corresponding author

\author{
Alexandra Braga and Vitor Braga \\ CETRAD, CIICESI, \\ Felgueiras School of Technology and Management, \\ Oporto Polytechnic, \\ Rua do Curral, Apt. 205, \\ Felgueiras 4610-156, Portugal \\ E-mail: abraga@estgf.ipp.pt \\ E-mail: vbraga@estgf.ipp.pt
}

\begin{abstract}
There is a general consensus that in a competitive business environment, firms' performance will depend on their capacity to innovate. To clarifying how, when and to what extent innovation affects the market and financial performance of firms, the authors deploy seemingly unrelated regression equation model to examine innovation in over 500 Portuguese firms from 1998 to 2004 . The results confirm, as theorists have frequently assumed, that innovation positively affects firms' performance; but they also suggest that the reverse is true, a result that is less intuitively obvious, given the complexity of the innovation process and local, national and global competitive environments.
\end{abstract}

Keywords: innovation; market and financial performance; determinants of innovation; CIS; community innovation survey; SURE; seemingly unrelated regression equation model.

Reference to this paper should be made as follows: Marques, C.S., Gerry, C., Covelo, S., Braga, A. and Braga, V. (2011) 'Innovation and the performance of Portuguese businesses: a 'SURE' approach', Int. J. Management and Enterprise Development, Vol. 10, Nos. 2/3, pp.114-128.

Biographical notes: Carla Susana Marques is an Assistant Professor of Management in the Department of Economics, Sociology and Management, University of Trás-os-Montes e Alto Douro (UTAD), Vila Real, Portugal. In her $\mathrm{PhD}$ in Management Science (UTAD, 2005), she evaluated Portuguese industrial firms' innovation strategies. She is the Coordinator of the 
'Innovation, Markets and Organisation' research group in UTAD's Centre for Transdisciplinary Development Studies (CETRAD). Her research on innovation and entrepreneurship has been presented at numerous international conferences and published in international journals such as Management Research, International Entrepreneurship and Management Journal and Journal of Management Research. She is a regular reviewer for the IberoAmerican Academy of Management (IAM), European Journal of Innovation Management and Int. J. Management and Information Technology. Her research interests include innovation (including social innovation), the management of change and entrepreneurship (particularly among women).

Chris Gerry is a Professor of Economic Theory and Policy in the Department of Economics, Sociology and Management, University of Trás-os-Montes e Alto Douro (UTAD), Vila Real, Portugal, Director of the Centre for Transdisciplinary Development Studies (CETRAD) and Dean of UTAD's School of Humanities and Social Science. His PhD in Economics from Leeds University (UK) focused on the relations between formal and informal enterprises in Dakar, the capital city of Senegal; on the basis of his research in Colombia, Chad, Kenya and Mozambique, he went on to publish numerous journal papers, book chapters and conference papers on urban poverty, microentrepreneurship, agro-industrial development and post-colonial transition. Coeditor with Ray Bromley of Casual Work and Poverty in Third World Cities and coauthor of Approaching Youth and Business: Entrepreneur Promotion vs. Sustainable Employment (with P.I. Panayiotopoulos), more recently his research has been devoted to small business development policy, youth employment strategies, and rural, regional and local development.

Susana Covelo is a Master's student in Management in the Department of Economics, Sociology and Management, University of Trás-os-Montes e Alto Douro (UTAD), Vila Real, Portugal, where she has worked as a Teaching Assistant. Currently, her research interests include the implications of innovation for organisational and institutional change.

Alexandra Braga is an Assistant Lecturer in Management at the Oporto Polytechnic's School of Technology and Management at Felgueiras (ESTGF), Portugal. She received her Master's degree in Management from UTAD in 2010 and is currently undertaking Doctoral Research in Management at Oporto University's School of Economics. She is a Research Assistant at UTAD's Centre for Transdisciplinary Development Research (CETRAD) and has presented the results of her research at international events organised by the Ibero-American Academy of Management (IAM) and International Conference for Entrepreneurship, Innovation and Regional Development (ICEIRD). Her research interests include entrepreneurship and the management of innovation.

Vitor Braga is an Associate Professor in Management at Oporto Polytechnic's School of Technology and Management at Felgueiras (ESTGF), Portugal, where he is the Director of the Business Sciences degree. In his PhD thesis in Business Economics (Middlesex University, London), he analysed business cooperation in the Portuguese small and medium enterprises (SMEs) in the furniture and the events-organisation sectors. Recently, he has been conducting research in entrepreneurship and, in particular, on informal cooperation mechanisms among Portuguese SMEs, as well as on innovation, institutional economics and spatial economics. He has presented his research widely at international conferences and publishes regularly in international journals. 


\section{Introduction}

Since innovation capacity is widely recognised as one of the main factors in the establishment and defence of a firm's competitive advantage, there is constant pressure not least of all due to the challenges, complexity and risks inherent in the management of innovation-for researchers to continue developing their understanding of how innovation influences firms' market and financial performance as well as the mechanisms through which the various groups of stakeholders involved in innovation initiate and pursue their involvement in the process.

From this perspective, innovation can be crucial not only for the sustainable performance of firms in financial and competitive terms, but also for the national economies of which - even in the era of globalisation - they form a part. Research in this field confirms that firms using innovation to improve their processes and/or to differentiate their products/services tend to experience better market and financial performance, measured in terms of market share, profitability, growth in sales turnover and market capitalisation (Bigler, 2009; Geroski and Reenen, 1993; Husso et al., 1996; Kleinknecht and Oostemdorp, 2002; Klemp et al., 2003; Klomp and Leeuwen, 1999; Koellinger, 2008; Marques and Monteiro-Barata, 2006; Peters, 2008). However, this same research has tended to be partial, inasmuch as it has not only typically focused on an incomplete list of relevant factors (Klemp et al., 2003; Klomp and Leeuwen, 1999; Nas and Leppälahti, 1997; Sandven and Smith, 2000), but also with few exceptions has concentrated on specific phases of the innovation process rather than the process as a whole. However, recent refinements in the definition and measurement of innovation may permit these limitations to be overcome: the factors associated with innovation can be disaggregated into their respective levels of intervention (macro, meso and micro) and can be categorised as relating to input, throughput and output phases (Marques and Monteiro-Barata, 2006). The research reported on in this paper uses these more recent conceptual approaches to innovation and its impact on market and financial performance to identify which factors have been most determinant in the performance of Portuguese firms for the period 1998-2003.

There are two main reasons for choosing to analyse the innovation process and its impact on economic and financial performance:

1 similar research has been conducted previously (see Marques and Monteiro-Barata, 2006) for an earlier period

2 it is natural for researchers to have a particular interest in studying their immediate environment (i.e. the national economy) to be able to propose improvements in management, strategy and policies.

From this perspective, this study can be seen as upgrading existing knowledge of entrepreneurial innovation processes and their impact, over a particular period of time, in a specific economy.

The choice of using the Portuguese Community Innovation Survey (CIS) data was based on two reasons. The first one was to provide the opportunity of contributing with findings and recommendations for the stakeholders' decision-making (both directly and indirectly), who are interested in learning about the impact of innovation on the performance of the firms located in a geographical area of interest for the authors. 
Secondly, it was aimed at applying this methodology to one country, so that further investigation can be applied to other European countries in which CIS data is available.

This paper is structured as follows: following an introductory section, a theoretical discussion of the approaches to innovation processes and their impact on economic and financial performance is provided; this paper then proceeds in the conventional manner with sections on method, results, discussion and conclusions, respectively. The research's main limitations and some avenues for future research, as well as implications for management practice, are also explored.

\section{Theoretical background and hypotheses}

Innovation is currently a central topic not only in the literature on management, but also in management practice itself, a fact that Bouchikhi and Kimberly (2001) have encapsulated in two key statements:

1 firms must innovate to survive, otherwise they disappear

2 the wide acknowledgement of this imperative and the difficulty of both stimulating and supporting firms' innovation and entrepreneurship have given rise to a small research and consultancy industry focusing specifically on management aspects of these topics.

In their opinion, "innovation may well be said to be one of the main topics of research and consultancy nowadays" (Bouchikhi and Kimberly, 2001, pp.77-78). More so than ever before, the concept of innovation has come to acquire an intrinsically positive meaning, both in practical and theoretical terms, i.e. innovation is good in itself.

In spite of the inherent risk and uncertainty involved, when successful, innovation tends to transmit beneficial effects to the firm's market and financial performance, effects that, in principle, can be transmitted to consumers as a whole. Innovation can therefore be seen as a key element both in firms' efforts to improve their market and financial performance and in the efforts of national economies to improve their overall competitiveness.

Nevertheless, the apparently uncontentious phrase that 'innovation improves a firm's performance' hides a complexity that has yet to be thoroughly researched: there exists a number of interacting factors - from the macro level to the micro level - that are far from simple and frequently the object of theoretical and empirical dispute, including the rates of economic growth a given nation is able to sustain, its overall competitiveness, the competitive strategies of its flagship companies and their long-term profitability, and the performance and sustainability of the mass of firms of all sizes and characteristics that make up the national economy.

To date, most empirical research on the determinants of firms' profitability has adopted the general analytical framework first developed in seminal studies by Schumpeter $(1934,1939)$. According to the Schumpeterian view of competition as a dynamic process that spreads throughout and even beyond a given industry, new products are developed, new markets are penetrated, new raw materials come into use and new forms of business organisation are adopted, with the transitory monopolistic profits that initially accrue to the innovator gradually declining as the improvements are adopted both by imitators within the industry and by new market entrants (Bartoloni, 2009). 
Recent research confirms that, by adopting strategies of innovation, businesses are able to improve their market and financial performance as measured by market share and profitability (e.g. Koellinger, 2008; Peters, 2008; Marques and Monteiro-Barata, 2006; Peters, 2008) or by growth and market capitalisation (e.g. Kleinknecht and Oostemdorp, 2002; Klemp et al., 2003; Klomp and Leeuwen, 2001; Koellinger, 2008). However, little attention has been paid in the research to the precise mechanisms by which innovation impacts on the market and financial performance of firms and frequently the range of variables included in the analysis has been incomplete. From this standpoint, the following hypothesis can be proposed with specific regard to the national economy selected for analysis:

$H_{0}^{(1)}$ : Innovation has a beneficial impact on the market and financial performance of Portuguese firms and vice versa, by way of positive interactions between the various phases of the innovation process (input, output and performance).

Conclusions drawn from recent studies in this field would suggest that a number of variables have a decisive impact in each phase of the innovation process and therefore, contribute differentially to overall improvements in a firm's performance.

While the most commonly used variable in the input phase of innovation is growth in research and development (RandD) expenditure (e.g. Coad and Rao, 2007; Klomp and Leeuwen, 2001; Lööf et al., 2001; Marques and Monteiro-Barata, 2006; Masso and Vahter, 2007), this measure has the disadvantage of excluding firms who have not invested in RandD in the past (Kleinknecht, 2000). Authors, such as Klomp and Leeuwen (1999), Kleinknecht (2000), Lööf et al. (2001), Kleinknecht and Oostendorp (2002), Klemp et al. (2003), Marques and Monteiro-Barata (2006), Masso and Vahtern (2007), Coad and Rao (2007) and Santos (2009), have opted to use total investment in innovation as the variable that best represents the firm's efforts in this regard at the input phase of the process, since it takes into account the process of innovation transformation (throughput), output and market/financial performance. On this basis, a first hypothesis was proposed:

$H_{0}^{(l a)}$ : The input phase of innovation is influenced by transformation processes (throughput), input determinants and overall firm performance.

Many of the studies that have sought to test the relationship between innovation outputs and firm performance (e.g. Bartoloni, 2009; Boia, 2003; Klemp et al., 2003; Koellinger, 2008; Lööf et al., 2001; Marques and Monteiro-Barata, 2006) have used the variable 'percentage of new product sales in total sales' to measure the outcome of innovation practices. However, given the availability in the CIS III and IV of data on various types of innovation, it was decided that, for this study, 'innovation output' could be best measured by aggregating outputs for both technological and non-technological innovation (e.g. in products, processes, marketing, markets and business organisation). On this basis, a second hypothesis was suggested:

$H_{0}^{(l b)}$ : Performance in the output phase of innovation is influenced by input determinants, transformation processes and overall firm performance. 
The literature underpinning this study (e.g. Bartoloni, 2009; Kleinknecht and Mohnen, 2002; Klemp et al., 2003; Lööf, 2000; Phusavat, 2007) suggests that innovating firms experienced improved rates of growth of both sales and profits. Furthermore, firms that cooperate in innovation on a permanent basis (e.g. those with stable relations in contiguous links of the value-added chain) can also expect to experience increased sales (e.g. Marques and Monteiro-Barata, 2006; Peters, 2008). Consequently, 'growth of sales' would seem to be the most appropriate variable to use when portraying the overall performance of our sample of companies. Hence, a third hypothesis was posited:

$H_{0}^{(I c)}$ : The growth in a firm's sales is influenced by output and by other performancerelated variables.

Recently, there has been a large amount of research about the different ways of defining and measuring innovation. On the one hand, innovation variables can be separated into macro, meso and micro variables and, on the other hand, into input, throughput and output variables. The research reported on here focuses on the micro level and distinguishes between innovation inputs, the transformation of inputs into outputs (here designated 'throughput') and innovation outputs. Using the hypothesis indicated above, our aim is to empirically investigate if innovation has had a positive impact on Portuguese firms' performance, using a model of innovation in four phases, based mainly on research conducted by Kline and Rosenberg (1986), Crépon et al. (1998), Marques and Monteiro-Barata (2006), as summarised as follows:

First phase

Second phase

Third phase

Fourth phase
The firm's decision to innovate or not is analysed on the assumption that several factors will influence the innovation output

The model examines the innovation decision, and the influence this has over levels of innovation inputs, and the corresponding expenditures to be made

The transformation of the innovation input into innovation output (throughput) occurs between the second and third phases; the model assesses innovation output achieved in the light of the innovation inputs expended

The model examined the relationship between innovation output and firms' market and financial performance

Since the innovation process involves a series of feedbacks (see Figure 1), innovation output, as measured by the firm's performance, not only may affect the level of investment in innovation, but the firm's market and financial performance may also influence all of the three preceding phases of innovation. Seen in this way, the precise mechanisms involved in the overall process can be examined by way of econometric methods like simultaneous equation regression. Furthermore, the philosophy underlying the construction of the European Union's (EU) CIS, which provided the panel data used in this study, is consistent with the application of such methods, which have already been used by authors such as Klemp et al. (2003) and Marques and Monteiro-Barata (2006). 
Figure 1 Global research model

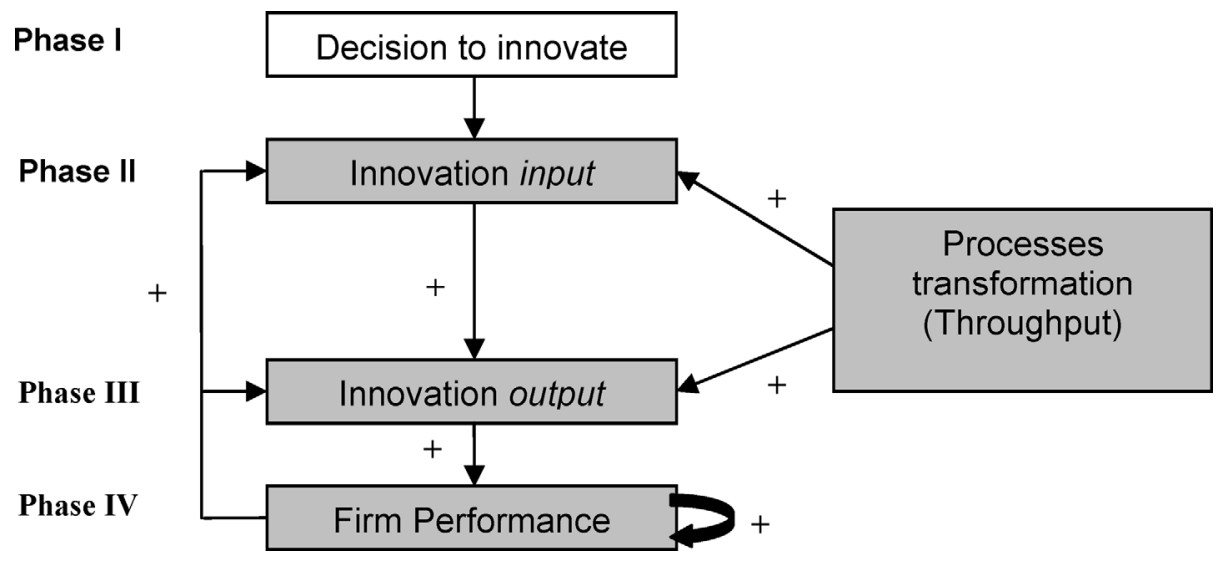

Source: Adopted from Marques and Monteiro-Barata (2006, p.118).

\section{Data and empirical methodology}

\subsection{Data set}

The most appropriate way of gaining access to longitudinal data on the innovation experience of a substantial sample of firms was to use the secondary data collected as part of the EU's CIS, a survey coordinated by EUROSTAT and undertaken, in the Portuguese case, by the Planning, Strategy and International Relations Evaluation Office (GPEARI) of the Ministry of Science, Technology and Higher Education (MCTES). Drawing on the CIS III and CIS IV databases for the periods 1998-2000 and 2002-2004, respectively, a sample of over 500 firms from the primary, secondary and tertiary sectors was constructed, including enterprises in rural and urban locations, both with and without experience of innovation, as indicated in Table 1.

\subsection{Empirical method}

The research model discussed above was deployed to identify the factors influencing each phase of innovation and to investigate whether feedback existed between any of the phases. In more recent studies on this question, the neoclassical vision of innovation and linear types of models appear to have been substituted by more complex conceptualisations that foreground not only a wider range of investments by the firm (including those in training, marketing, design and image, cooperation and networking, for example), but also the details of the process of knowledge creation. Thus the traditional notion of the profit-maximising firm is replaced by that of the learning organisation, which functions under conditions of bounded rationality, and uses both its own internal competencies and networks established with other entities (upstream, downstream, competitors, public and private support institutions, etc.) within a specific geographical space. 
Innovation and the performance of Portuguese businesses

Table 1 Sample overview (508 observations)

\begin{tabular}{|c|c|c|c|c|c|c|}
\hline & \multicolumn{3}{|c|}{ CIS III } & \multicolumn{3}{|c|}{ CIS IV } \\
\hline & Rural & Urban & Total & Rural & Urban & Total \\
\hline Total firms (no.) & 178 & 330 & 508 & 178 & 330 & 508 \\
\hline Primary sector (\%) & 2.8 & 2.7 & 2.8 & 2.8 & 2.7 & 2.8 \\
\hline Secondary sector $(\%)$ & 73.6 & 66.4 & 68.7 & 73.6 & 66.4 & 68.7 \\
\hline Tertiary sector (\%) & 24.2 & 30.9 & 28.5 & 24.2 & 30.9 & 28.5 \\
\hline Micro firms (\%) & 0 & 0 & 0 & 0 & 0.9 & 0.6 \\
\hline Small firms (\%) & 32.6 & 29.1 & 30.3 & 33.1 & 29.4 & 30.7 \\
\hline Medium firms (\%) & 33.1 & 30.9 & 31.7 & 23.6 & 29.7 & 27.6 \\
\hline Large firms $(\%)$ & 34.3 & 40.0 & 38.0 & 43.3 & 40.0 & 41.1 \\
\hline SME (\%) & 65.7 & 60.0 & 62.0 & 56.7 & 59.1 & 58.3 \\
\hline Innovative firms: yes (\%) & 74.7 & 80.0 & 78.1 & 70.8 & 74.8 & 73.4 \\
\hline Product innovation (\%) & 36.0 & 40.9 & 39.2 & 38.2 & 48.8 & 42.5 \\
\hline Process innovation $(\%)$ & 44.9 & 43.6 & 44.1 & 47.8 & 51.2 & 50.0 \\
\hline Other innovations $(\%)$ & 62.9 & 70.9 & 68.1 & 47.2 & 60.0 & 55.5 \\
\hline $\begin{array}{l}\text { Innovation in products and } \\
\text { processes }(\%)\end{array}$ & 4.5 & 1.8 & 2.7 & 7.3 & 5.8 & 6.3 \\
\hline $\begin{array}{l}\text { Innovation strategy: } \\
\text { innovation in the market (\%) }\end{array}$ & 27.5 & 336 & 31.5 & 24.2 & 28.8 & 27.2 \\
\hline Job creation: yes $(\%)$ & 39.9 & 32.7 & 35.2 & 39.9 & 32.7 & 35.2 \\
\hline
\end{tabular}

Source: Authors' CIS database.

When analysing aspects of innovation that involve interaction between the four phases of the process of innovation (input, throughput, output and performance), more complex econometric methods, such as those incorporated into the probit, tobit and Heckman models and those using simultaneous equations, are recommended. In studies involving feedback relations, it is common to use two-stage and three-stage models (Lööf et al., 2001; Klomp and Leeuwen, 2001, respectively), both of which use least squares to estimate pre-defined simultaneous equations. In the study of Portuguese industrial firms conducted by Marques and Monteiro-Barata (2006), the seemingly unrelated regression equation (SURE) model was used to estimate the simultaneous equations that summarised potential feedback relations between input, output and firm performance. Taking into account the conceptual and methodological issues presented above and the characteristics of the data set, it was decided to apply the same SURE approach to the CIS panel data. The variables involved in the innovation process as well as their principal characteristics are presented in Table 2. 
Table 2 Innovation process variables and their characteristics

\begin{tabular}{|c|c|c|}
\hline Variables & Description & Scale \\
\hline \multicolumn{3}{|l|}{ Input } \\
\hline Innovation effort & Total investment in innovation & Interval \\
\hline Training for innovation & Percentage of investment in training for innovation & Interval \\
\hline \multicolumn{3}{|l|}{ Throughput } \\
\hline Innovation strategy & Innovation as part of the strategy & Dichotomous \\
\hline Market & Dummy variable - performance in the market & Dichotomous \\
\hline Customer & Dummy variable - customer satisfaction & Dichotomous \\
\hline Cooperation & $\begin{array}{l}\text { Dummy variable - cooperation with research } \\
\text { institutions and other firms }\end{array}$ & Dichotomous \\
\hline \multicolumn{3}{|l|}{ Output } \\
\hline Innovation & Process/product/market/organisational innovation & Dichotomous \\
\hline \multicolumn{3}{|l|}{ Performance } \\
\hline Growth in sales & Evolution of sales growth between 1998 and 2004 & Interval \\
\hline Growth in employment & Evolution of job creation rate between 1998 and 2004 & Interval \\
\hline Location & Rural vs. urban & \\
\hline Size & Small, medium and large firms & \\
\hline Sector & Primary, secondary and tertiary & \\
\hline Funding & $\begin{array}{l}\text { The existence of external funding (supporting } \\
\text { programmes and other sources of funding) }\end{array}$ & \\
\hline
\end{tabular}

Source: Authors' CIS database.

\section{The simultaneous equation model of the relations between innovation and firm performance}

To detect the existence of feedback relations between the phases of the innovation process, a model using three simultaneous equations was adopted with a SURE approach being used to estimate the parameters of the regression. Table 3 summarises the estimation results.

Having used the specific version of the SURE method developed by Zellner (1962) to analyse the three equations, the following conclusions were drawn:

1 the equation reflecting 'total investment in innovation' is influenced by innovation output (i.e. innovation in process, product, market and organisation) and by the firm's performance (as measured by growth in sales turnover)

2 the equation reflecting 'innovation output' is influenced by innovation input, as measured by total expenditure on innovation and on associated (re)training, by the innovation process (i.e. recourse to cooperation and support networks) and by the firm's performance (as measured by growth in sales turnover)

3 the equation reflecting 'firm performance' is influenced by innovation output (i.e. innovation in process, product, market and organisation) and by the performance variable relating to job creation. 
Table 3 Results of the estimation of the simultaneous equation model

\begin{tabular}{llll}
\hline & Innovation input & Innovation output & Growth in sales \\
\hline $\begin{array}{l}\text { Total investment in } \\
\text { innovation }\end{array}$ & - & $3,069.814^{* * *}(1.83)$ & - \\
Training for innovation & $0.0610^{* *}(2.82)$ & $0.243^{*}(4.12)$ & - \\
Cooperation & - & $0.197 *(3.43)$ & - \\
Innovation output & - & - & $0.632 *(5.65)$ \\
Growth in sales & $0.0382 *(3.46)$ & $0.167 *(5.65)$ & - \\
Employment growth & - & - & $0.212 * * *(1.84)$ \\
Size & $0.098 *(2.86)$ & $0.313 *(3.31)$ & - \\
Funding & - & $0.134 * *(2.24)$ & - \\
Constant & $0.0174 *(2.56)$ & - & $0180 * * *(0.72)$ \\
$\chi^{2}$ & 76.54 & 26.31 & 28.72 \\
Probabilty $>\chi^{2}$ & 0.0003 & 0.0049 & 0.0071 \\
Adjusted $R^{2}$ & 0.7510 & 0.6540 & 0.7180 \\
\hline
\end{tabular}

Note: $t$-Statistics always appear between round brackets.

Significance level at which the null hypothesis is rejected $* 1 \% ; * * 5 \%, * * * 10 \%$.

Only statistically significant results are presented in this table.

Model estimated by the SURE method.

Source: Authors' CIS database.

These conclusions demonstrate that feedback exists between the various phases of innovation (input, output and performance), thereby confirming one of the interactions proposed in the research model $\left(H_{0}^{(1)}\right)$, namely that innovation impacts positively on Portuguese firms' performance and vice versa.

It should also be stressed that, in contrast to some studies (e.g. Rothwell and Dodgson, 1994, on the North of Europe; and Veciana, 2002, on Spain), firm size emerged here as a statistically significant variable in the regression equations. For Portugal, however, these studies have produced somewhat different results with authors such as Conceição et al. (2003), Monteiro-Barata (2004) and Marques and Monteiro-Barata (2006) reporting no such relationship between firm size and innovation. This ambiguity or rather this difference in results for different countries - requires further investigation, some suggestions on which are provided in Section 5.

\section{Conclusion, implications and suggestions for future research}

The results summarised in Figure 2 confirm the hypotheses of the study demonstrating that innovation on the part of Portuguese firms has a positive effect on their market and financial performance and vice versa, and that there exists positive feedback between the input, output and performance phases of the innovation processes undertaken by them. 
Figure 2 Results of the global research model (see online version for colours)

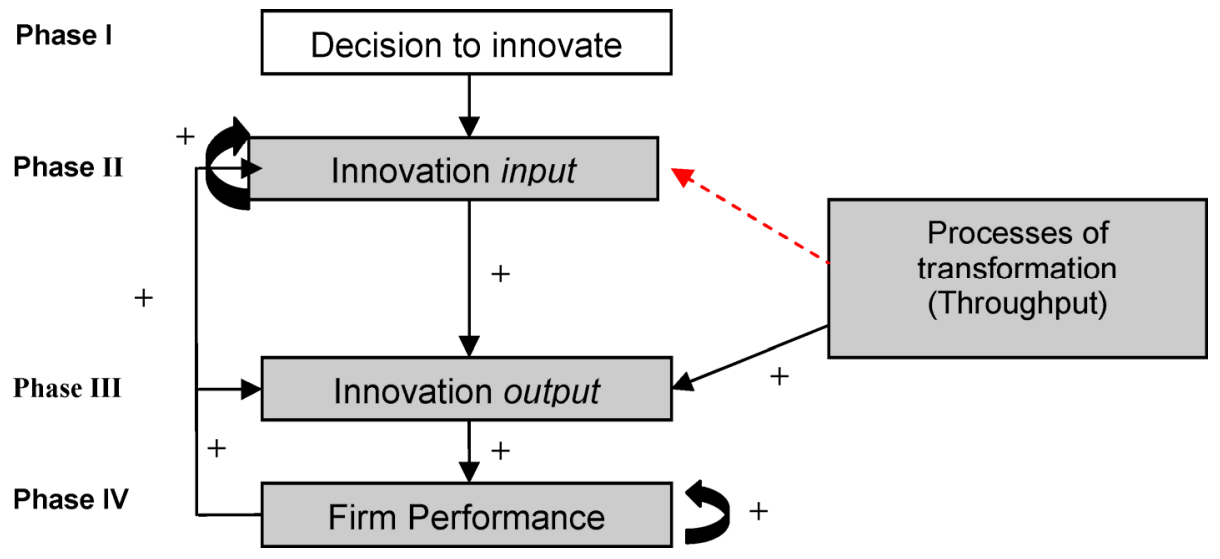

Source: Authors' results.

Understanding the precise relationship linking innovation and firm performance is not only important for the leadership of individual companies, but also for planning and policy at the national level. This study has gone some way in clarifying this interrelationship for a small national economy with quite specific structural characteristics and with its own particular historical pace and trajectory of innovation and may therefore provide some basis for comparison with other cases. The findings of this research suggest that Schumpeterian competition is still prevalent, i.e. that innovation (among various measures of efficiency) strongly influences the explained variance in firms' profitability rates, supporting idea that government policy that promotes innovation may have a significant impact on enterprise performance, thereby helping to foster growth and competitiveness not only among businesses, but also in specific regions and in the economy at large. Furthermore, the empirical evidence suggests which of the specific practices that form part of the overall innovation process are most responsible, in this case, for generating positive effects on corporate performance and which should, therefore, be adopted by firms currently that are either not innovating or are underperforming in this regard.

In general terms, since innovation - seen as a continuous entrepreneurial strategy - is a key source of competitive advantage, firms should not only intensify their efforts in this regard, but may also use firms with successful innovation performance to benchmark the general contours and specific detail of their own innovation strategies. More specifically, since the study also revealed cooperation to be a determining factor in innovation, initiatives such as the constitution of consortia for the incorporation of applied research in new products and processes, and active participation in innovation networks are to be encouraged. Networks not only facilitate access to information, but also allow firms to more easily assess the value of adhering to government and other innovation support programmes, as well as promoting the upstream, downstream and cluster-based interaction between service providers, clients and competitors that is vital to optimising information on production factors, markets and the overall competitive environment. 
Collectively coordinated interaction between the various stakeholders in an innovation system permits a closer match to be established between the innovation needs of businesses and the corresponding institutional support structure and policy environment. From this perspective, governments should:

1 promote increased and more intensive information- and knowledge-sharing between firms and other stakeholders in the innovation system, thereby allowing institutional and policy support for innovation to be more easily evaluated, accessed and improved

2 create specific measures conducive to the promotion of innovation on the part of the small and micro enterprises ${ }^{1}$ that constitute the vast majority of businesses in Portugal, ${ }^{2}$ in particular, the fostering and consolidation of long-term relationships between firms with and without RandD and related innovation experience, and encouraging universities and other RandD centres to tailor their practices and strategies more closely to the needs of SMEs in general and small and micro enterprises, in particular

3 support entrepreneurship in general and business start-ups in particular by facilitating access to risk capital, one of the key elements to overcoming the innovation barrier

4 reduce the costs of patenting new ideas and adapt the existing legal framework to make it more conducive to the commercial exploitation of innovation

5 develop measures to support the provision of key services to innovative firms (supply side) and the acquisition of such services by innovating firms (demand side).

Five important limitations of this study would need to be overcome in future research:

1 Collection of longitudinal data relating to a longer time period would permit other factors (such as profitability and growth) to be included in the analysis, as well as for the time lag between innovation and its impact on performance to be more precisely assessed.

2 The relatively limited number of observations generated by a survey of a small economy such as Portugal makes statistical control of all of key variables difficult (e.g. scale of the firm and its sector of activities).

3 Limiting the application of the research to Portugal, which can, in the future, be extended to other European countries.

4 To specify more clearly the interaction between the variables studied and to identify other factors influencing the relationship between innovation and market and financial performance, it would be appropriate to complement analysis of panel data with case studies involving more detailed qualitative interviews. In the first place, the panel data available from EU sources seems to virtually exclude micro firms, i.e. those with fewer than ten employees; secondly, case studies could be designed to focus on possible differences between various scales of enterprise (micro, small, medium and large) on more specifically defined sectors (e.g. traditional industrial vs. technology-based services) and locations (rural vs. urban; metropolitan vs. more peripheral regions) and on innovation processes in firms within specific clusters and firms in successive links of the value chain. 
5 As suggested by Armbruster et al. (2008), a larger (or different) battery of innovation indicators would allow comparison with studies (such as the large scale surveys conducted by NUTEK, DRUID, EPOC, INNFORM and COI) that employed other types of indicators (e.g. relating to organisational and marketing innovation) and other measures of performance (e.g. skilled employment created) (Mothe and Thi, 2010).

It is almost inconceivable that in a highly competitive and globalised business environment, firms can generate sustainable growth without innovating. Nevertheless, while well-performing businesses of different types innovate to different extents and with differential success, many firms with apparent potential for growth appear to do little more than survive without innovating at all. If building and consolidating competitiveness is a strategic aim, then innovation is a strategic imperative for company and country alike. From this perspective, all the corporate and institutional stakeholders in the innovation system need to be constantly aware of the importance of coordinating their activities and initiatives if businesses located within national frontiers are to benefit from a dynamic and adaptable innovative environment.

\section{References}

Armbruster, H., Bikfalvib, A., Kinkela, S. and Lay, G. (2008) 'Organizational innovation: the challenge of measuring non-technical innovation in large-scale surveys', Technovation, Vol. 28, pp.644-657.

Bartoloni, E. (2009) 'Profitability and innovation: new empirical findings based on Italian data 1996-2003', Available at: http://www2.druid.dk/conferences/viewpaper.php?id=5421 andcf= 32, Accessed on January 2010.

Bigler, W.R. (2009) 'Strategy execution through executive process innovation: a longitudinal case example and research model', Int. J. Management and Enterprise Development, Vol. 7, No. 4, pp.394-408.

Boia, M. (2003) 'Determinants of innovation in Portugal: designing, implementing and analysing evidence from the third community innovation survey', PhD Dissertation, Instituto Superior Técnico (IST/UTL), Lisbon, Portugal.

Bouchikhi, H. and Kimberly, J. (2001) 'It's difficult to innovate': the death of the tenured professor and the birth of the knowledge entrepreneur', Human Relations, Vol. 54, No. 1, pp.77-84.

Coad, A. and Rao, R. (2007) 'Innovation and firm growth in high tech sectors: a QUantile regression approach', Laboratory of Economics and Management, Sant'Anna School of Advanced Studies, Pisa, Italy.

Conceição, P., Heitor, M. and Veloso, F. (2003) 'Infrastructures, incentives and institutions: fostering distributed knowledge bases for the learning society', Technological Forecasting and Social Change, Vol. 70, No. 7, pp.583-617.

Crépon, B., Duquet, E. and Mairesse, J. (1998) 'Research, innovation and productivity: an econometric analysis at the firm level', NBER Working Paper, No. 6696.

European Commission (2003) 'Recommendation No. 361', Available at: http://ec.europa. eu/enterprise/policies/sme/facts-figures-analysis/sme-definition/index_en.htm, Accessed on January 2010.

Geroski, P. and Reenen, J. (1993) 'The profitability of innovating firms', RAND Journal of Economics, Vol. 24, No. 2, pp.198-211.

Husso, K., Leppälahti, A. and Niininen, P. (1996) R\&D, Innovation and Firm Performance: Studies on the Panel Data of Finnish Manufacturing Firms, Vol. 3. Helsinki: Statistics Finland, Science and Technology. 
INE - Instituto Nacional de Estatística (2010) Estudos sobre Estatísticas Estruturais das Empresas. Lisbon, 30 June.

Kleinknecht, A. (2000) 'Indicators of manufacturing and service innovation: their strengths and weaknesses', in J. Metcalf and I. Miles (Eds.), Innovation System and the Service Economy. Boston: Kluwer AP, pp.169-186.

Kleinknecht, A. and Mohnen, P. (2002) Innovation and Firm Performance: Econometric Explorations of Data Survey Data. Basingstoke: Palgrave.

Kleinknecht, A. and Oostemdorp, R. (2002) 'RandD and export performance: taking account of simultaneity', in A. Kleinknecht and P. Mohnen (Eds.), Innovation and Firm Performance. London: Palgrave, pp.310-320.

Klemp, R., Folkeringa, M., Jong, J. and Wubben, E. (2003) 'Innovation and firm performance', Research Report H200207 SCALES.

Kline, S. and Rosenberg, N. (1986) 'An overview of innovation', in R. Landau and N. Rosenberg (Eds.), The Positive Sum Strategy: Harnessing Technology for Economic Growth. Washington, DC: National Academic Press, pp.275-305.

Klomp, L. and Leeuwen, G. (1999) 'The importance of innovation for company performance', Netherlands Official Statistics, Vol. 14, pp.26-35.

Klomp, L. and Leeuwen, G. (2001) 'Linking innovation and firm performance: a new approach', Int. J. Economics of Business, Vol. 8, No. 3, pp.343-364.

Koellinger, P. (2008) 'The relationship between technology, innovation, and firm performance: empirical evidence on e-business in Europe', Available at: http://publishing.eur.nl/ir/repub/ asset/12469/ERS-2008-031-ORG.pdf, Accessed on January 2010.

Lööf, H. (2000) 'Outsourcing, innovation and performance in service and manufacturing industries', Conference on Innovation and Enterprise Creation: Statistics and Indicators, France.

Lööf, H., Heshmati, A., Asplund, R. and Naas, S. (2001) 'Innovation and performance in manufacturing industries: a comparison of the Nordic countries', SSE/EFI Working Paper Series in Economics and Finance, No. 457, p.38.

Marques, C. and Monteiro-Barata, J. (2006) 'Determinants of the innovation process: an empirical test for the Portuguese manufacturing industry', Management Research, Vol. 4, No. 2, pp.111-124.

Masso, J. and Vahter, P. (2007) 'Innovation and firm performance in a catching-up economy', Available at: http://www.merit.unu.edu/MEIDE/papers/2007/MASSO_VAHTER_Innovation $\% 20$ and $\% 20$ firm\%20performance\%20in\%20a\%20catching-up\%20economy.pdf, Accessed on January 2010.

Monteiro-Barata, J. (2004) 'Innovation in the Portuguese manufacturing industry: analysis of a longitudinal company panel', 57th International Atlantic Economic Conference, Lisbon.

Mothe, C. and Thi, T. (2010) 'The link between non-technological innovations and technological innovation', European Journal of Innovation Management, Vol. 13, No. 3, pp.313-332.

Nas, S. and Leppälahti, A. (1997) 'Innovation, firm profitability and growth', STEP Report 1/97.

Peters, B. (2008) Innovation and Firms' Performance: An Empirical Investigation for German Firms. Springer.

Phusavat, K. (2007) 'Roles of performance measurement in SMEs' management processes', Int. J. Management and Enterprise Development, Vol. 4, No. 4, pp.441-458.

Rothwell, R. and Dodgson, M. (1994) The Handbook of Industrial Innovation. UK: Edward Elgar.

Sandven, T. and Smith, K. (2000) 'Innovation and economic performance at the enterprise level', Conference on Innovation and Enterprise Creation: Statistics and Indicators, Sophia Antipolis, France, 23-24 November 2000.

Santos, D. (2009) A Influência da Inovação no Desempenho das Firmas no Brasil. São Paulo, Brazil: Presbiterana Mackenzie University. 
Schumpeter, J. (1934) The Theory of Economic Development. Cambridge: Harvard University Press.

Schumpeter, J. (1939) Business Cycles: A Theoretical, Historical and Statistical Analysis of the Capitalist Process (2nd ed.). New York: McGraw-Hill.

Veciana, J. (2002) La Innovación como Reto para la Gestión y la Investigación. Covilhã, Portugal: XII Jornadas Luso-Espanholas de Gestão Científica.

Zellner, A. (1962) 'An efficient method of estimating seemingly unrelated regressions and tests for aggregation bias', Journal of American Statistical Association, Vol. 57, pp.348-368.

\section{Notes}

${ }^{1}$ The European Commission's (2003) Recommendation No. 361 defines small and medium enterprises as follows:

\begin{tabular}{lcl}
\hline Enterprise category & No. of employees & Sales turnover or balance sheet total \\
\hline Medium & $<250$ & $\leq € 50$ million OR $\leq € 43$ million \\
Small & $<50$ & $\leq € 10$ million OR $\leq € 10$ million \\
Micro & $<10$ & $\leq € 2$ million OR $\leq € 2$ million \\
\hline
\end{tabular}

${ }^{2}$ According to the government's National Statistical Institute (INE, 2010), there are 349,746 Portuguese firms, $85.6 \%$ of which are micro enterprises, $12.2 \%$ are small firms, $1.9 \%$ are medium-sized companies and only $0.3 \%$ qualify as large enterprises. 